\title{
Estruturas de poder nas redes de financiamento político nas eleições de 2010 no Brasil
}

\author{
Rodrigo Rossi Horochovski \\ Ivan Jairo Junckes \\ Edson Armando Silva \\ Joseli Maria Silva \\ Neilor Fermino Camargo
}

\section{Introdução}

Este artigo relata resultados de investigação sobre a dinâmica de financiamento de campanha das eleições de 2010 no Brasil ${ }^{1}$. Aos dados do Tribunal Superior Eleitoral (TSE), aplicamos a metodologia de análise de redes sociais (ARS) e tratamentos estatísticos complementares, com que realizamos uma descrição topológica da rede composta por 299.968 relacionamentos estabelecidos entre os 251.665 atores (doadores e/ou receptores) de recursos financeiros em todos os cargos em disputa naquelas eleições.

No Brasil, a literatura sobre financiamento eleitoral também demonstra que o acesso a recursos financeiros é um dos fatores determinantes para viabilizar uma candidatura vitoriosa (Samuels, 2001; Speck, 2005; Figueiredo Filho, 2009; Peixoto, 2009, Mancuso, 2015). Com esta pesquisa, identificamos a posicionalidade de cada um dos candidatos, financiadores e agentes partidários ${ }^{2}$ e analisamos como a topologia da rede se relaciona com o desempenho desses atores ${ }^{3}$.

O foco das preocupações recai sobre financiadores que tendem a "investir" recursos em determinados candidatos visando manter e/ou aumentar sua influência sobre as decisões políticas de seu interesse. Afinal, de acordo com Ohman (2014, p. 2), "em todo o mundo, cresce gradualmente a convicção de que uma eleição bem administrada não pode fazer nada pela democracia se o resultado é decidido pelo dinheiro ao invés do voto".

\footnotetext{
1 O artigo resulta de projetos financiados pelo CNPq e pela Fundação Araucária sobre Financiamento Político e Análise de Redes Sociais. Versão preliminar foi apresentada na Área Temática Eleições e Representação Política, no IX Encontro da Associação Brasileira de Ciência Política (ABCP), realizado em 2014, em Brasília (DF). Agradecemos a Bruno Wilhelm Speck os comentários. Expressamos nosso reconhecimento também a Renato Perissinotto pela leitura paciente e as sugestões ao manuscrito, assim como aos pareceristas anônimos de Opinião Pública, cujas observações possibilitaram significativas melhorias no texto.

${ }^{2}$ Assim denominados os diretórios partidários e comitês financeiros agregados por partido em cada unidade da federação.

3 Os relatórios de rede gerados a partir do banco de dados podem ser encontrados em $<$ http://www.getepolitica.org/>.
} 
Os relacionamentos estabelecidos pelos agentes financiadores e receptores de recursos nos certames eleitorais indicam muito mais que a viabilidade das candidaturas apoiadas e o potencial de retorno dos investimentos. Em rede, eles revelam uma estrutura de poder, para a qual dirigimos um conjunto de questões:

- Como os recursos se distribuem entre os participantes da rede de financiamento?

- Como os atores estão posicionados em termos de centralidade e periferia na dinâmica de financiamento eleitoral?

- Em que medida o posicionamento dos atores se relaciona com o desempenho na eleição e com o acesso privilegiado ao processo decisório?

A hipótese que orientou a investigação é a de que, para além dos montantes envolvidos, a ocupação de posições centrais e privilegiadas na teia de relacionamentos, constituída pelo financiamento de campanha, está relacionada a maiores chances eleitorais dos candidatos e à assertividade dos doadores em identificar e financiar o conjunto de candidaturas mais exitosas. Para testar essa hipótese, lançamos mão da análise de redes sociais (ARS).

A ARS permitiu a observação dos fluxos de relações entre os milhares de agentes que participam do processo. O enfoque é complementar a perspectivas apoiadas em atributos de candidatos ou grupos - como recursos monetários, partido, gênero, renda, ocupação, escolaridade, entre outros -, adotadas pela maioria das pesquisas sobre financiamento político, dentre as quais podemos destacar, além das já citadas, as de Cervi (2010), Sacchet e Speck (2012), Peixoto (2014) e Speck e Mancuso (2014).

Nosso "material básico" é a rede de financiamento eleitoral de 2010, com cerca de 300 mil transações financeiras, estabelecidas entre mais de 250 mil agentes. A Tabela 1 traz a distribuição dos participantes dessa rede:

Tabela 1

Agentes participantes na Rede de financiamento eleitoral de 2010

\begin{tabular}{|l|c|c|}
\hline \multicolumn{1}{|c|}{ Agente } & N & \% \\
\hline Financiadores pessoas físicas & 207.827 & 82,6 \\
\hline Financiadores pessoas jurídicas & 21.719 & 8,6 \\
\hline Candidatos & 21.577 & 8,6 \\
\hline Agentes partidários & 542 & 0,2 \\
\hline Total & 251.665 & 100,0 \\
\hline
\end{tabular}

Fonte: Brasil - Tribunal Superior Eleitoral (TSE). Prestação de contas 2010 [online]. Disponível em:

<http://www.tse.jus.br/eleicoes/estatisticas/repositorio-dedados-eleitorais>. Acesso em: 14 set. 2014.

A rede resultante dos relacionamentos estabelecidos entre o conjunto dos nós pode ser visualizada na Figura 1. No grafo, os agentes doadores estão representados por 
pontos/nós vermelhos, os candidatos por pontos/nós azuis e os relacionamentos de fluxo financeiro, ou seja, as doações realizadas entre os agentes, por linhas/arestas verdes.

Figura 1

Grafo da rede de financiamento eleitoral de $\mathbf{2 0 1 0}$

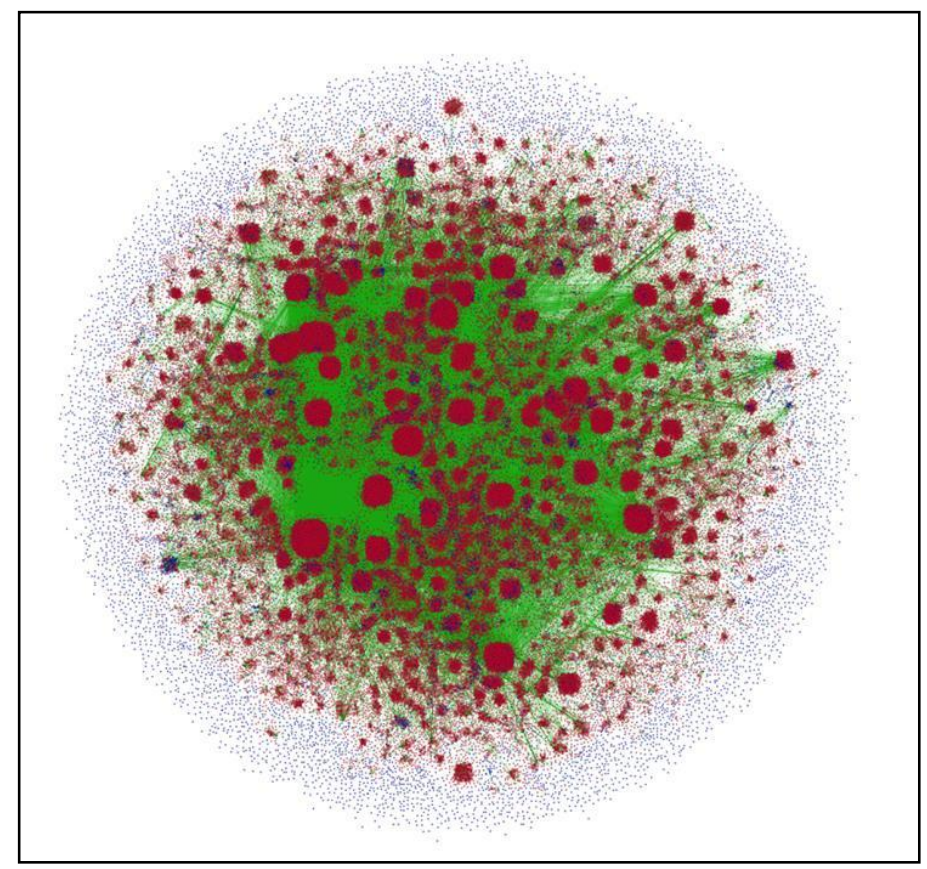

Fonte: Elaboração própria com base em dados do TSE (Brasil, 2014).

A Figura 1 expressa um desafio assumido pela presente investigação. Alguns de seus "pequenos" aglomerados de pontos vermelhos podem conter até 12 mil nós, inviabilizando o seu estudo pela simples visualização ou exploração convencional dos dados. Torna-se, portanto, fundamental o tratamento em banco de dados, a exploração sistemática por particionamentos e a realização de cálculos de topologia.

Os procedimentos adotados permitiram a análise da complexidade relacional da rede das eleições de 2010 e, consequentemente, dão pistas acerca da dinâmica estrutural do financiamento eleitoral no Brasil. A futura inclusão de outros pleitos no estudo poderá reforçar a compreensão do fenômeno.

Este artigo está dividido em três partes. A primeira é uma breve revisão da literatura sobre financiamento político e da metodologia de análise de redes sociais (ARS). A segunda parte analisa os resultados obtidos a partir da geração das redes, da identificação de seus componentes, dos cálculos de centralidade dos nós e de reduções e filtros que permitem a identificação de seus elementos estruturais. Por fim, sintetizamos os achados, à luz dos quais inferimos as principais estratégias dos agentes e debatemos 
sentidos teórico-epistemológicos para a agenda de estudos sobre financiamento político. Concluímos indicando possíveis desdobramentos da pesquisa.

\section{Financiamento político e análise de redes sociais}

A questão do financiamento político tem alcançado maior expressão nas últimas décadas, conforme pesquisadores observam que as práticas de sustentação militante se tornam residuais quando comparadas aos recursos oriundos de grupos de interesse, especialmente grandes conglomerados empresariais e financistas (Lodoño e Zovatto, 2014).

Como aponta Zovatto (2005, p. 289), "o tema do financiamento político se converteu em uma questão estratégica de toda democracia, e ao mesmo tempo, dada sua complexidade e os desafios que apresenta, também se tornou um problema, uma verdadeira dor de cabeça".

Ganha relevância o debate sobre as fontes de recursos e as vantagens e desvantagens do uso de financiamento privado ou estatal de campanhas eleitorais (Cervi, 2010, p. 3). Discute-se, ainda que de forma pouco conclusiva, o fato de os eleitos terem de "retribuir" doações feitas por apoiadores de suas campanhas, através de concessões a interesses corporativos específicos, seja no Executivo, seja no Legislativo.

Em análise sobre a relação entre recursos recebidos em campanha e o apoio de parlamentares à agenda de interesses da Confederação Nacional da Indústria (CNI) no Congresso Nacional, Santos et al. (2015, p. 52) não confirmaram a hipótese de influência do financiamento específico da indústria sobre o comportamento dos parlamentares nos assuntos específicos do setor, todavia verificaram que "quanto maior a proporção de recursos vindos de empresas, maior é a cooperação dos deputados em matérias de interesse do setor produtivo".

Em balanço abrangente da produção sobre o tema no Brasil, Mancuso (2015, p. 155) denomina o financiamento eleitoral de "investimento eleitoral", esclarecendo que "envolve tanto as contribuições eleitorais, feitas por financiadores de campanhas, quanto os gastos eleitorais, feitos pelos candidatos e seus partidos ou comitês, a partir das contribuições recebidas".

No tocante ao relacionamento entre recursos e resultados, Mancuso (2015, p. 158) aponta que, para uma importante parte da bibliografia brasileira, "a hipótese central é de que há associação positiva e estatisticamente significativa entre arrecadação e gasto eleitoral, de um lado, e desempenho eleitoral, de outro lado".

A relação entre recursos e benefícios de retribuição para financiadores tem sido explorada mais recentemente, concentrando-se nos doadores empresariais e nos diferentes objetivos visados por esses agentes. O balanço em apreço não encontrou, no entanto, trabalhos que integrem os comitês e diretórios partidários à análise - os poucos que os consideram o fazem de forma segmentada. A presente investigação constitui, 
portanto, uma contribuição para os debates, sendo especialmente inovadora na última frente exploratória.

De um lado, ao assumir papel de intermediação entre as pessoas jurídicas, os grupos de interesse e os candidatos, as instâncias partidárias historicamente tenderam a eclipsar as relações entre candidaturas e seus financiadores. Em uma tentativa de alterar esse quadro, o TSE (Tribunal Superior Eleitoral) impôs, mediante a Resolução no 23.406/2014, a necessidade de identificação da origem dos recursos doados pelos partidos às candidaturas ${ }^{4}$.

De outro lado, o mesmo papel de intermediação revela o grau de ascensão dessas instâncias sobre os candidatos, dependentes de recursos para sua sobrevivência eleitoral, e evidenciam o canal através do qual os interesses corporativos se inserem nas instâncias decisórias. Em outras palavras, "eminências pardas" nas direções partidárias ganham poder e influência ao articular as relações entre candidatos e doadores privados que encontram neles um canal sempre aberto.

Os papéis de agente partidário burocratizado e de candidato formam redes complementares e interdependentes com seus financiadores. Tal composição de papéis permite aos partidos obter o aporte de estrutura necessária à disputa eleitoral sem comprometer politicamente suas lideranças carismáticas. Afinal, como afirma Sawicki (2013, p. 24), "são as posições e os papéis que ocupam os indivíduos no mundo social que Ihes abrem a possibilidade de se inserirem nas redes existentes e assim de modificarem eventualmente a forma delas. Não há, portanto, de um lado, o mundo da ação organizada e, do outro, o mundo das redes". Como seria possível, porém, identificar essas posições e papéis na rede?

Respondemos a essa questão aplicando a metodologia de análise de redes sociais aos dados de prestação de contas da campanha de 2010 no Brasil ${ }^{5}$. Todavia, nada é tão simples e direto. O processamento dos dados em programa de análise de redes ${ }^{6}$ apresentou um desafio inicial: a falta de normalização na forma como eles foram disponibilizados até 2012 pela Justiça Eleitoral. Atores que podiam receber doações e realizar despesas às vezes as declaravam sem informar os identificadores únicos de doadores e fornecedores, sendo necessário apenas zerar a relação entre receitas e despesas, de um lado, e facilitar a fiscalização do ponto de vista contábil, de outro.

Uma consequência desse modelo original de organização dos dados referentes ao pleito de 2010 era a inexistência de um identificador único que permitisse capturar um ator de modo inequívoco em diferentes planilhas de prestação de contas. Diante disso, foi necessário desenvolver, para este artigo, um banco de dados normalizado, relacionando precisamente as informações mediante técnicas de mineração de dados que

\footnotetext{
${ }^{4}$ Para compreender o quadro normativo do financiamento de campanhas e prestação de contas, ver Lima (2012) e Schlickmann (2014).

${ }^{5}$ Disponíveis no repositório do Tribunal Superior Eleitoral (TSE) em:

<http://www.tse.jus.br/eleicoes/estatisticas/repositorio-de-dados-eleitorais>.

${ }^{6}$ Optamos por empregar o Gephi, software livre disponível em <www.http://gephi.github.io/>.
} 
possibilitaram a identificação unívoca dos atores nos diversos registros disponibilizados pelo TSE e sua organização em uma rede relacional complexa.

A Figura 2 - grafo resultante da agregação por tipo dos atores que formam a rede de 2010 - expressa o resultado geral da pesquisa, permitindo a visualização da dinâmica descrita anteriormente. Ele propicia compreender a trajetória dos recursos nesse pleito eleitoral.

Figura 2

\section{Grafo da rede de financiamento das eleições de 2010 no Brasil, nós agregados por tipo de ator}

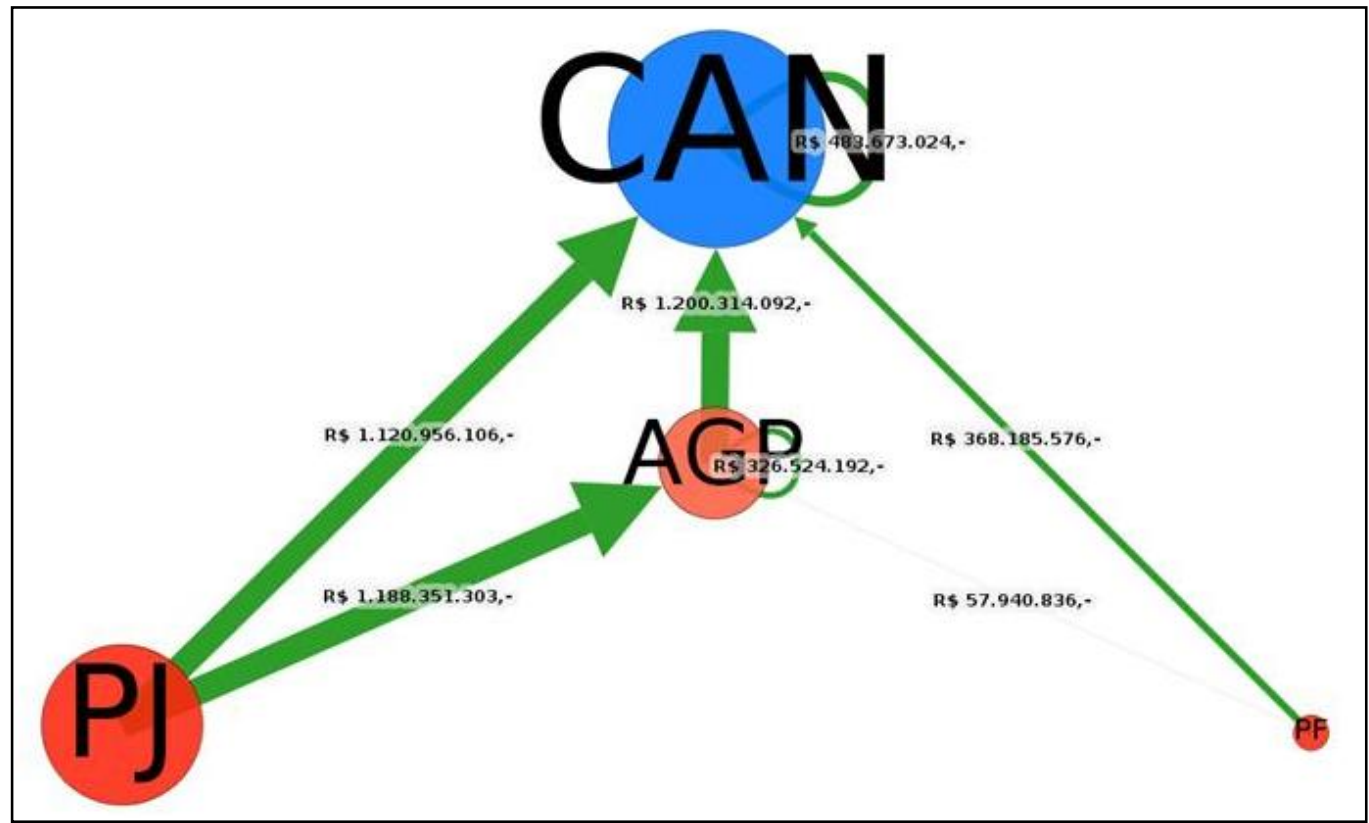

Fonte: Elaboração própria com base em dados do TSE (Brasil, 2014).

Na Figura 2, a espessura das arestas é proporcional ao montante de recursos nos fluxos $^{7}$. Note-se que o peso das arestas que ligam agentes partidários a candidatos é semelhante ao peso das arestas que ligam pessoas jurídicas aos partidos. Por sua vez, as transferências entre agremiações partidárias entre si (loops) e de candidatos entre si (loops) revelam a dimensão estratégica de busca de aliados no pleito eleitoral, o que acontece também nas transferências das agremiações partidárias diretamente para os candidatos.

Os nós estão dimensionados de acordo com o volume de recursos - de saída, no caso dos doadores, e de entrada, no caso dos candidatos. O que mais chama a atenção é a diferença em termos de volume entre os recursos viabilizados por pessoas jurídicas

\footnotetext{
${ }^{7}$ Os valores financeiros relativos às eleições de 2010 foram mantidos como se encontravam nas planilhas de prestação de contas, sem atualização.
} 
quando comparados com aqueles oriundos de pessoas físicas, apesar de estas serem muito mais numerosas.

A análise da rede de financiamento de 2010 permitiu descrever esses fluxos através do exame da topologia e dos fluxos preferenciais na rede, evidenciando a capacidade de influência de cada grupo de agentes e as estratégias dos financiadores na alocação de recursos aos partidos.

Embora a demonstração gráfica dessas dinâmicas a partir das estratégias dos partidos não possa ser apresentada nos limites deste artigo, vale a pena apontar que a metodologia de análise de redes permite descrever o grau de recursos viabilizados pelos mesmos financiadores ou então intermediados pelas mesmas instâncias partidárias, permitindo inferir o grau de conexão entre partidos em suas estratégias eleitorais.

Além das coligações formais, o compartilhamento de recursos permite verificar, de maneira concreta, a proximidade ou afastamento de suas estratégias eleitorais, ou, diversamente, constatar que um dos fatores que influenciam na decisão de formalizar uma coligação seja justamente a possibilidade de partilhar recursos de campanha demonstramos tal dinâmica em artigo anterior (Horochovski et al., 2015).

Redes complexas, como a rede de financiamento eleitoral, apresentam tendência de grande variação na quantidade e na intensidade de relações entre os nós, de modo que é necessário produzir recortes, agregações e projeções para tornar inteligíveis as respostas às perguntas que fazemos à base de dados. Isso é realizado através de um conjunto de ferramentas que estabelecem para cada ator a sua localização primária e as medidas de seu posicionamento na rede. No escopo deste artigo, entretanto, nos dedicamos à identificação dos componentes gigante e isolados e à aplicação das medidas de centralidade: grau, proximidade, intermediação e autovetor.

Componentes são sub-redes de nós conectados entre si, i.e., no qual há caminhos pelos quais é possível chegar a qualquer nó partindo-se de qualquer outro nó. $\mathrm{O}$ estudo dos componentes possibilita explorar diferentes conectividades no interior de uma rede.

Em redes com elevado número de nós, é comum um dos componentes, chamado de gigante, ser formado pela maioria, ou mesmo a quase totalidade, dos nós. Os nós entre $F$ e $O$, na Figura 3, formam um conjunto desse tipo. Os demais componentes, ou sub-redes - em geral constituídos por apenas um nó (casos de $C, D$ e $E$ ), por díades ( $A$ $B$ ) ou tríades e eventualmente por quatro ou mais nós -, são chamados de componentes isolados (Newman, 2010; Batagelj, 2011). 
Figura 3

Grafo ilustrativo de componentes de rede

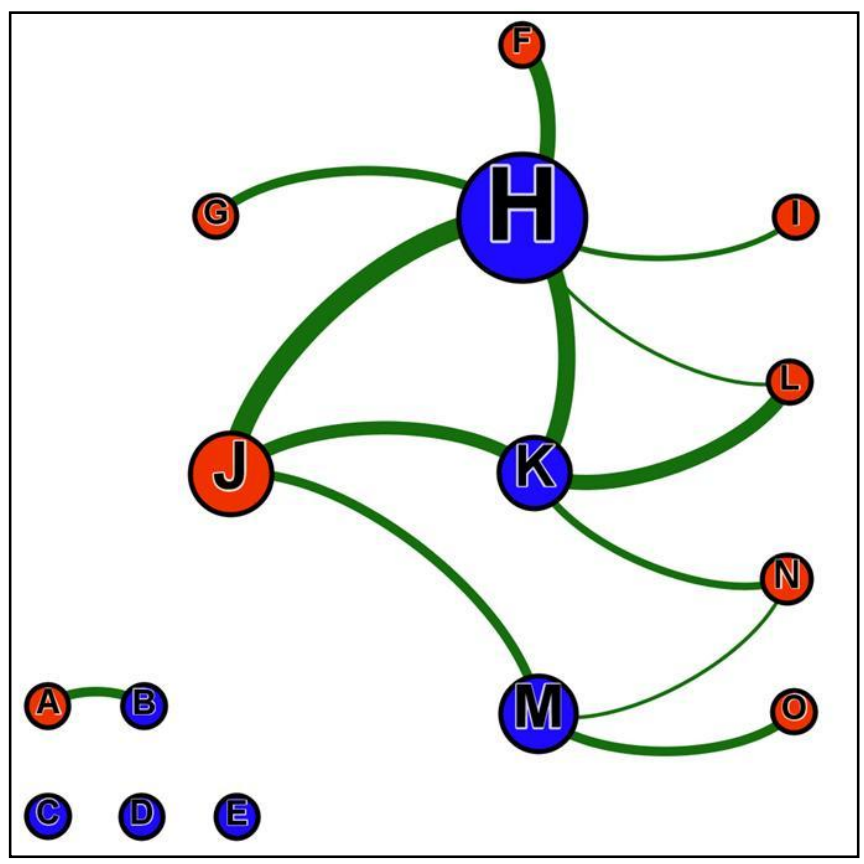

Fonte: Elaboração própria.

A rede de financiamento eleitoral de 2010 é formada por um componente gigante que congrega mais de $90 \%$ dos nós da rede e também por milhares de pequenos componentes isolados. A partir da rede geral (Figura 1), foram extraídos dois grafos, integralmente complementares (Figura 4), que representam o componente gigante e os 7.273 componentes isolados: 


\section{Figura 4 \\ Grafos de componentes (gigante e isolados) da rede de financiamento das eleições de 2010 no Brasil}

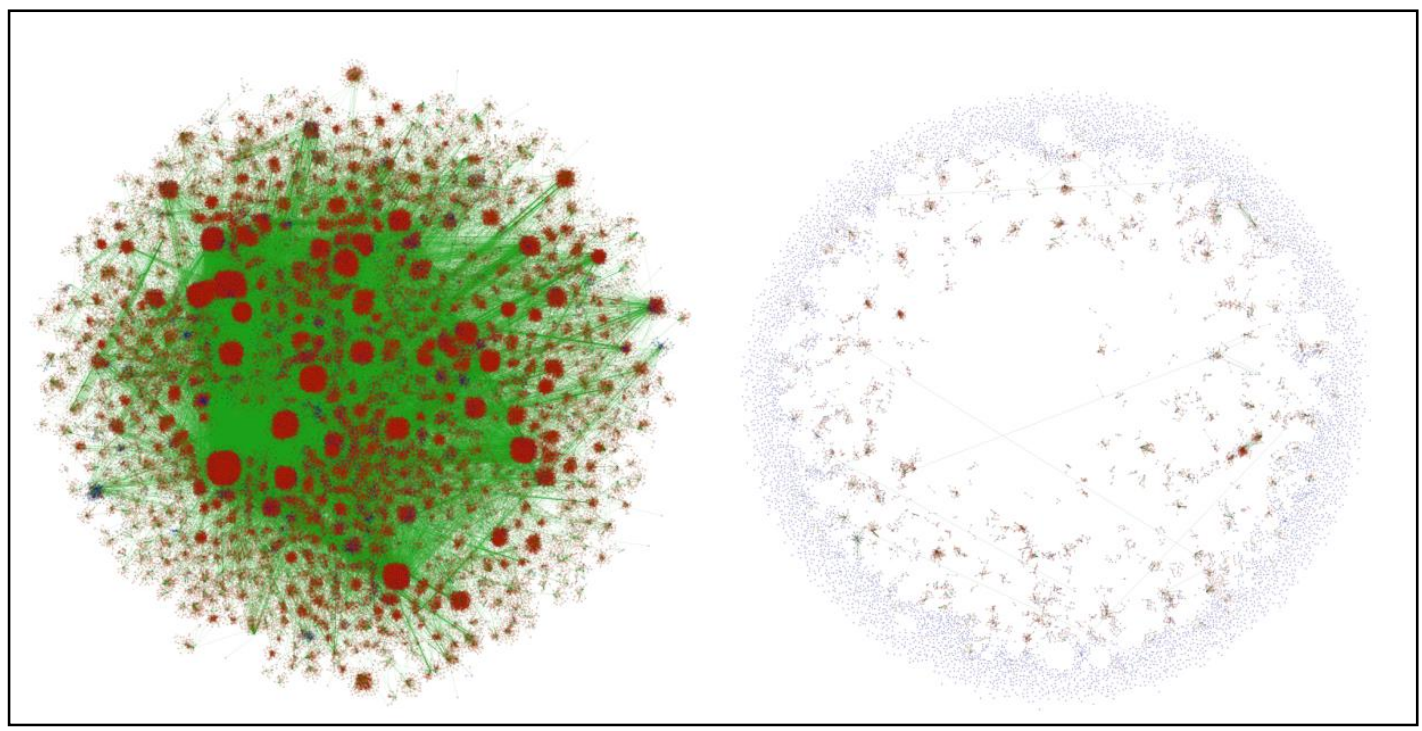

Fonte: Elaboração própria com base em dados do TSE (Brasil, 2014), distribuição OpenOrd.

A importância dessa identificação reside no fato de que, em regra, os jogadores mais importantes de uma rede social apresentam ampla conectividade, raramente se encontrando fora do componente gigante. É neste que podemos evidenciar a estrutura ocultada pela complexidade das relações. A partir dele, executamos cálculos de centralidades que permitem identificar o posicionamento dos atores na rede por diversos critérios.

De forma bastante simplificada, a centralidade de grau leva em consideração o número de vínculos; a centralidade de proximidade considera a distância entre um ator e o conjunto dos participantes; a centralidade de intermediação mede a frequência com que um nó se coloca no caminho mais curto entre todos os demais atores da rede. $\mathrm{Na}$ Figura 3, $H$ é o ator mais central nas três medidas dentro de seu componente.

A centralidade de autovetor está relacionada ao posicionamento de um ator nas vizinhanças de outros atores centrais. $J$ exerce esse papel, em função da proximidade que desfruta de $H$ e $L$, conectores importantes da sub-rede. Freeman (1979) traz essas definições e Degenne e Forsé (2007, p. 132-139) explicam os respectivos algoritmos de cálculo.

Ordenamos os resultados dos cálculos de centralidade por quartis e os relacionamos com a situação final de urna (candidatos eleitos e não eleitos), por meio de testes estatísticos de razão de chances (odds ratio) ${ }^{8}$.

\footnotetext{
${ }^{8}$ Para tanto, usamos o pacote estatístico gratuito Past, disponível em:

<http://nhm2.uio.no/norlex/past/download.html>.
} 
Os testes foram suficientemente significativos e robustos para estabelecermos relações entre os rankings de posicionalidade na rede e desempenho dos candidatos. Os dados das centralidades dos financiadores mostraram também a assertividade dos investimentos desses agentes. Adicionalmente, aplicamos filtros de redução, que apontaram um núcleo estrutural de poder dentro da rede.

\section{Resultados}

A rede examinada está subdividida em 7.274 componentes, conforme detalhado na Tabela 2, com um componente gigante que abarca praticamente a totalidade da rede.

Optamos por excluir das análises o autofinanciamento de candidatos, ou seja, os loops que ocorrem quando um candidato doou para a sua própria campanha. Embora tais "transações" sejam expressivas - são 9.562 casos que somam R\$322.334.196,00 - elas não compõem, neste momento dos estudos, fator explicativo inter-relacional. Todavia, sinalizam para a necessidade de exploração futura desse fenômeno, pois $44 \%$ dos candidatos da rede realizaram autodoação, sendo que entre os eleitos esse porcentual alcança $83 \%$ com a expressiva média individual de $\mathrm{R} \$ 92.778,45$.

Tabela 2

Agentes e transações - Componente gigante e componentes isolados

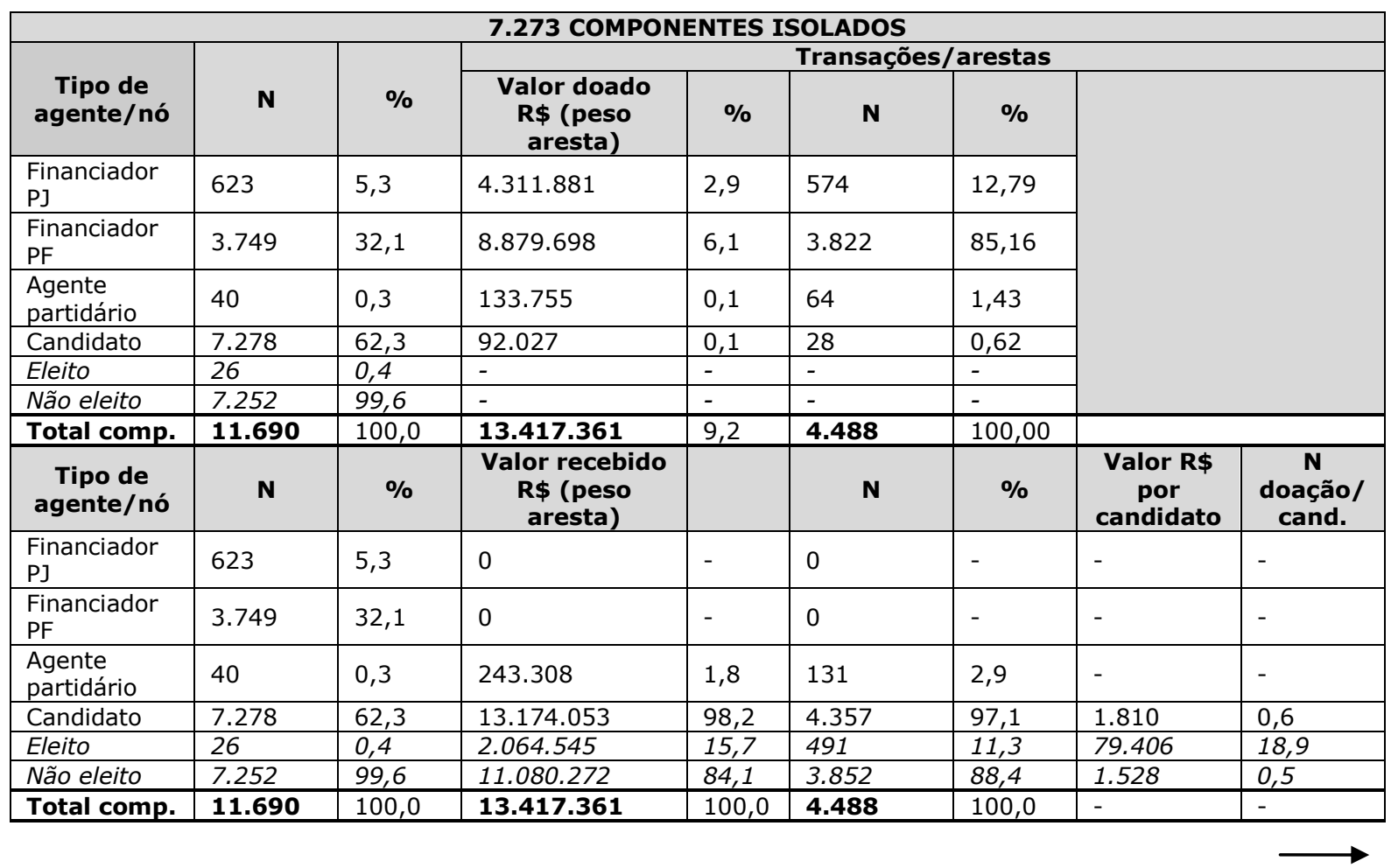


ESTRUTURAS DE PODER NAS REDES DE FINANCIAMENTO POLÍTICO NAS ELEIÇÕES DE 2010 NO BRASIL

\begin{tabular}{|c|c|c|c|c|c|c|c|c|}
\hline \multicolumn{9}{|c|}{ COMPONENTE GIGANTE } \\
\hline \multirow[b]{2}{*}{$\begin{array}{c}\text { Tipo de } \\
\text { agente/nó }\end{array}$} & \multirow[b]{2}{*}{$\mathbf{N}$} & \multirow[b]{2}{*}{$\%$} & \multicolumn{6}{|c|}{ Transações/arestas } \\
\hline & & & $\begin{array}{l}\text { Valor doado } \\
\text { R\$ (peso } \\
\text { aresta) } \\
\end{array}$ & $\%$ & N doação & $\%$ & & \\
\hline $\begin{array}{l}\text { Financiador } \\
\text { PJ }\end{array}$ & 21.096 & 8,8 & 2.304 .995 .528 & 53,4 & 38.036 & 13,3 & & \\
\hline $\begin{array}{l}\text { Financiador } \\
\text { PF }\end{array}$ & 204.078 & 85,0 & 417.246 .714 & 9,7 & 219.312 & 76,7 & & \\
\hline $\begin{array}{l}\text { Agente } \\
\text { partidário }\end{array}$ & 502 & 0,2 & 1.371 .572 .404 & 31,8 & 13.009 & 4,6 & & \\
\hline Candidato & 14.299 & 6,0 & 218.943 .108 & 5,1 & 15.402 & 5,4 & & \\
\hline Eleito & 1.625 & 0,7 & - & - & - & - & & \\
\hline Não eleito & 12.674 & 5,3 & - & - & - & - & & \\
\hline Total comp. & 225.676 & 100,0 & 4.312 .757 .754 & 100,0 & 270.357 & 100,0 & & \\
\hline $\begin{array}{c}\text { Tipo de } \\
\text { agente/nó }\end{array}$ & $\mathbf{N}$ & $\%$ & $\begin{array}{c}\text { Valor recebido } \\
\text { R\$ (peso } \\
\text { aresta) } \\
\end{array}$ & $\%$ & N doação & $\%$ & $\begin{array}{c}\text { Valor R\$ } \\
\text { por } \\
\text { candidato }\end{array}$ & $\begin{array}{c}\text { N } \\
\text { doação/ } \\
\text { cand. }\end{array}$ \\
\hline $\begin{array}{l}\text { Financiador } \\
\text { PJ }\end{array}$ & 21.096 & 9,35 & 0 & & 0 & - & - & - \\
\hline $\begin{array}{l}\text { Financiador } \\
\text { PF }\end{array}$ & 204.078 & 90,43 & 0 & & 0 & - & - & - \\
\hline $\begin{array}{l}\text { Agente } \\
\text { partidário }\end{array}$ & 502 & 0,22 & 1.475 .137 .189 & 34,2 & 24.432 & 8,6 & - & - \\
\hline Candidato & 14.299 & 6,34 & 2.837 .620 .565 & 65,8 & 261.302 & 91,4 & 198.449 & 18,3 \\
\hline Eleito & 1.625 & 11,4 & 1.636 .504 .460 & 57,7 & 122.334 & 46,8 & 1.007 .080 & 75,3 \\
\hline Não eleito & 12.674 & 88,6 & 1.201 .116 .105 & 42,3 & 138.900 & 53,2 & 94.770 & 11,0 \\
\hline Total comp. & 225.676 & 100,00 & 4.312 .757 .754 & 100,0 & 285.734 & 100,0 & - & - \\
\hline $\begin{array}{l}\text { Razão de } \\
\text { chances* }\end{array}$ & $\begin{array}{l}\text { Odds ratio } \\
95 \% \text { confic } \\
z: 3,7193 \\
p(\text { ratio }=1) \\
\end{array}$ & $\begin{array}{l}30,94 \\
\text { ence: }[5,0 \\
0,000199\end{array}$ & $\begin{array}{l}. .188,8] \\
6\end{array}$ & & & & & \\
\hline
\end{tabular}

Fonte: Elaboração própria com base em dados do TSE (Brasil, 2014).

* Eleitos - componente gigante $\mathrm{x}$ componentes isolados.

\section{Identificando atores periféricos a partir dos componentes isolados}

A exploração dos componentes isolados permite analisar o conjunto dos atores mais periféricos e, como podemos constatar adiante, com menor expressão eleitoral. Os 11.690 nós que formam esses componentes estão subdivididos em 623 financiadores pessoas jurídicas, 3.749 financiadores pessoas físicas, 40 agentes partidários e 7.278 candidaturas $^{9}$.

Apenas 969 componentes isolados apresentam alguma conexão. Contendo 5.386 nós, esse conjunto resulta em média inferior a seis agentes/nós por componente. Trata-

\footnotetext{
${ }^{9}$ Ainda que o gênero dos candidatos não seja o foco deste artigo, uma interessante constatação emergiu da análise dos componentes isolados: neles, há 5.049 homens $(69,4 \%)$ e 2.229 mulheres $(30,6 \%)$, ou seja, o grupo de candidaturas a ocupar posições mais periféricas é o único na rede de financiamento no qual se atinge a cota de gênero imposta pela Lei Eleitoral, tal qual demonstraram Junckes at al. (2015) em estudo sobre o posicionamento das mulheres na rede de 2010.
} 
se de pequenos grupos políticos desconectados entre si, como, por exemplo, partidos de pequeno porte e seus candidatos com um reduzido número de financiadores.

Os demais 6.304 componentes são formados por candidatos/nós solitários que financiaram sua própria campanha ou candidatos que prestaram contas sem registro de doação, tornando-se nós sem nenhuma ligação e, portanto, com centralidade de grau zero (são os pontos isolados do grafo à direita na Figura 4).

Dos 1.651 candidatos eleitos em 2010, parcela ínfima pertence aos componentes isolados: $26(1,5 \%)$, sendo cinco deputados federais e 21 deputados estaduais. Vale destacar, ainda, que, mesmo estando em componentes isolados, as médias de valores recebidos são expressivamente superiores entre os poucos eleitos, $R \$ 79.406$, contra $R \$$ 1.528 para os não eleitos.

Apenas uma candidatura bem-sucedida é um nó solitário, embora candidaturas totalmente isoladas sejam seis vezes mais frequentes do que aquelas com alguma conectividade dentro dos componentes isolados. Essa topologia evidencia milhares de atores ainda mais periféricos entre os já periféricos.

Esses achados evidenciam um traço estrutural relevante da rede de financiamento eleitoral de 2010: pertencer a um componente isolado, ou seja, estar desconectado do componente gigante acarreta drástica redução das possibilidades de êxito: um candidato no componente gigante tem quase 31 vezes mais chances de estar entre os eleitos do que um em componente isolado (cf. teste de razão de chances (odds ratio) presente na Tabela 2, comparando os eleitos nos componentes). Isso indica que buscar os atores centrais na topologia da rede implica examinar detidamente o componente gigante.

\section{O componente gigante: locus do núcleo político-empresarial e do sucesso eleitoral}

O componente gigante é formado por 239.975 nós e 285.759 arestas, contendo, respectivamente, $95,4 \%$ e $98,5 \%$ da rede investigada. Esses dados exprimem outra característica estrutural da rede: o financiamento político no Brasil é altamente integrado.

Através de 2.147.483.647 de caminhos "curtos" (shortest paths), qualquer um dos atores do componente gigante está conectado com qualquer outro desse mesmo grupo. Isso significa que qualquer doador ou candidato do estado do Rio Grande do Sul está ligado por algum caminho na rede com qualquer outro ator dos estados do Acre, Roraima ou Amapá. Com os recursos de análise de redes é possível identificar todos esses caminhos com relativa simplicidade.

Podemos afirmar, portanto, que o tamanho e a complexidade do país não são óbices à integração entre financiadores, partidos e candidatos, sendo possível explorar essa impressionante conectividade com as ferramentas disponibilizadas pela metodologia de análise de redes. 
O componente gigante aglutina 14.299 candidaturas, sendo 11.685 homens $(81,7 \%)$ e 2.614 mulheres $(18,3 \%)$ (nesse conjunto, as cotas legais de gênero ficaram longe de ser atendidas). Os financiadores somam 225.174 subdivididos em 204.078 pessoas físicas e 21.096, jurídicas. Identificamos, ainda, 502 atores agentes partidários (direções partidárias e comitês financeiros agregados por partido em cada unidade da federação).

Nota-se clara diferença de perfil quando se coteja a distribuição dos atores por tipo nos componentes isolados e no componente gigante (Figura 5). Neste, há maior concentração relativa de financiadores, enquanto naqueles observa-se maior proporção de candidatos.

\section{Figura 5}

Gráficos de distribuição por tipos de agente nos componentes

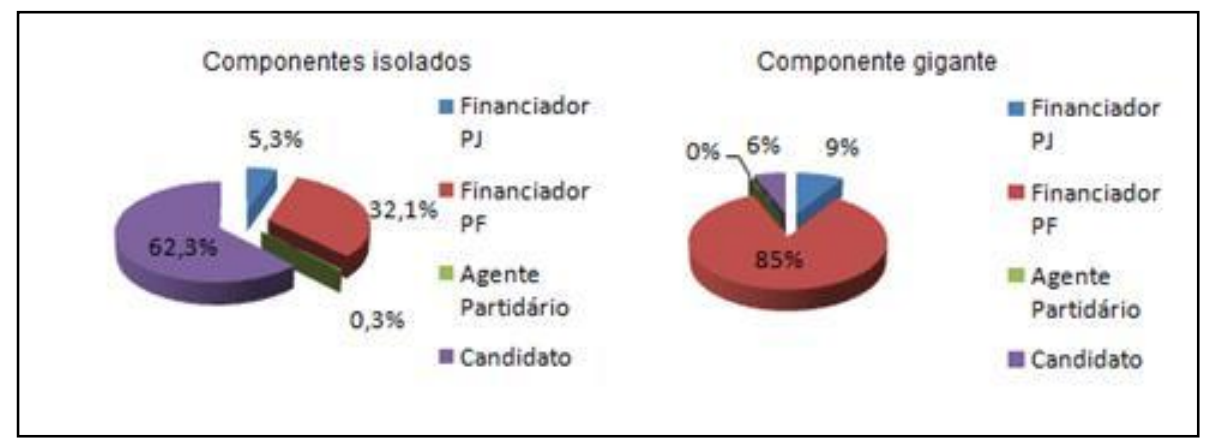

Fonte: Elaboração própria com base em dados do TSE (Brasil, 2014).

Dos 1.651 candidatos eleitos, 1.625 , ou seja, 98,5\%, estão posicionados no componente gigante, sendo 1.436 homens $(88,4 \%)$ e 189 mulheres $(11,6 \%)$. Ainda que se considere a maior quantidade de candidaturas nesse componente, o teste de razão de chances anterior demonstra que é praticamente condição sine qua non para o sucesso eleitoral constituir relações no componente gigante.

$\mathrm{Na}$ medida em que o componente em apreço abrange milhares de relacionamentos e nós da rede, uma topologia mais nítida demanda uma classificação ordenada de seus elementos. Para tanto, são imprescindíveis as medidas de centralidade.

A análise de redes permite estabelecer a posicionalidade e, ato contínuo, os papéis dos atores de uma rede a partir das medidas de centralidade definidas na seção anterior "Financiamento político e análise de redes sociais". Iniciamos a exposição sob o prisma das candidaturas para, em seguida, explorar as perspectivas dos financiadores privados e agentes partidários.

Optamos por proceder à análise mais refinada das candidaturas a partir dos quartis superior (terceiro) e inferior (primeiro) dos candidatos ordenados segundo cada uma das medidas de centralidade. A Tabela 3 registra os resultados, comentados em sequência: 
Tabela 3

Centralidades médias e razões de chances eleitorais nos quartis superiores e inferiores de centralidades (grau, proximidade, intermediação)

Candidatos componente gigante

\begin{tabular}{|c|c|c|c|c|c|c|c|c|c|c|c|c|}
\hline \multirow{3}{*}{ Quartil } & \multicolumn{4}{|c|}{ Grau } & \multicolumn{4}{|c|}{ Proximidade } & \multicolumn{4}{|c|}{ Intermediação } \\
\hline & \multirow{2}{*}{$\begin{array}{c}\text { Central. } \\
\text { média }\end{array}$} & \multicolumn{2}{|c|}{ Eleitos } & \multirow{2}{*}{$\begin{array}{c}\text { Rec. } \\
\text { média } \\
\text { R\$ } \\
1.000\end{array}$} & \multirow{2}{*}{$\begin{array}{l}\text { Central. } \\
\text { média* }\end{array}$} & \multicolumn{2}{|c|}{ Eleitos } & \multirow{2}{*}{$\begin{array}{c}\text { Rec. } \\
\text { média } \\
\text { R\$ } \\
1.000\end{array}$} & \multirow{2}{*}{$\begin{array}{l}\text { Central. } \\
\text { média* }\end{array}$} & \multicolumn{2}{|c|}{ Eleitos } & \multirow{2}{*}{$\begin{array}{c}\text { Rec. } \\
\text { média } \\
R \$ \\
1.000\end{array}$} \\
\hline & & $\mathbf{N}$ & $\%$ & & & $\mathbf{N}$ & $\%$ & & & $\mathbf{N}$ & $\%$ & \\
\hline Superior & 66,39228 & 1326 & 81,6 & 731,51 & 0,21851 & 971 & 59,8 & 688,51 & 0,02212 & 1279 & 78,7 & 721,23 \\
\hline Inferior & 1,21924 & 9 & 0,5 & 22,73 & 0,16158 & 122 & 7,5 & 15,47 & 0 & 9 & 0,5 & 11,77 \\
\hline \multirow{4}{*}{$\begin{array}{l}\text { Razão de } \\
\text { chances** }\end{array}$} & \multicolumn{4}{|c|}{ Odds ratio: 147,33} & \multicolumn{4}{|c|}{ Odds ratio: 7,959} & \multicolumn{4}{|c|}{ Odds ratio: 142,11} \\
\hline & \multicolumn{4}{|c|}{ 95\% confidence:[76,36..284,3] } & \multicolumn{4}{|c|}{ 95\% confidence: $[6,556 . .9,662]$} & \multicolumn{4}{|c|}{ 95\% confidence: $[73,65 . .274,2]$} \\
\hline & \multicolumn{4}{|c|}{$z: 14,89$} & \multicolumn{4}{|c|}{$z: 20,968$} & \multicolumn{4}{|c|}{$\mathrm{z}: 14,781$} \\
\hline & \multicolumn{4}{|c|}{$p($ ratio $=1): 3,8093 \mathrm{E}-50$} & \multicolumn{4}{|c|}{$\mathrm{p}($ ratio $=1): 1,2739 \mathrm{E}-97$} & \multicolumn{4}{|c|}{$\mathrm{p}($ ratio $=1): 1,9464 \mathrm{E}-49$} \\
\hline
\end{tabular}

Fonte: Elaboração própria com base em dados do TSE (Brasil, 2014).

* Valores normalizados $[0,1] * *$ Eleitos - quartil sup. $\mathrm{x}$ quartil inf.

Como vimos anteriormente, centralidade de grau é a quantidade de vínculos/arestas ligadas a cada ator da rede, sendo mais central o ator que possuir mais vínculos e mais periférico o que registrar menos vínculos. Entre todos os eleitos no componente gigante, o grau médio é 79,9 , enquanto entre os não eleitos esse número se reduz a 11,6 .

Os resultados por quartis de centralidade são expressivos: o superior conta com 1.326 eleitos, ou $81,6 \%$; no inferior, são apenas nove eleitos $(0,5 \%)$ (Tabela 3 ). Pelo teste de razão de chances, inferimos que um candidato no quartil superior tem 147 vezes mais chances de se eleger que um integrante do quartil inferior. Depreendemos que centralidade de grau é fator de expressiva importância para o desempenho eleitoral, sendo a de maior poder explicativo para a rede estudada.

Embora não seja foco do artigo medir o impacto dos valores financeiros em si nas chances eleitorais, e mesmo correndo o risco de algum viés em função de considerarmos todas as candidaturas em distintos distritos, vale a pena uma rápida exploração das vinculações entre frequência de doações (ou seja, a centralidade de grau), volumes doados e viabilidade das candidaturas. Os candidatos no componente gigante receberam, em média, $\mathrm{R} \$ 219.202,81$, todavia, a média dos eleitos no mesmo componente foi de $\mathrm{R} \$$ $1.092 .883,09$, valor cinco vezes maior.

Considerando a tabela ordenada por centralidade de grau, o quartil superior apresenta média de $\mathrm{R} \$ 731.509,24$, enquanto no inferior, com 99,5\% de não eleitos, o valor cai para $\mathrm{R} \$ 22.733,77$.

A simples comparação entre os valores não apenas confirma que o volume dos recursos recebidos é determinante para a eleição, tal qual demonstraram diversas 
ESTRUTURAS DE PODER NAS REDES DE FINANCIAMENTO POLÍTICO NAS ELEIÇÕES DE 2010 NO BRASIL

pesquisas (por exemplo, Lemos, Marcelino e Pederiva, 2010, e Cervi, 2010), como também mostra a associação positiva entre as variáveis de centralidade de grau e volume de recursos recebidos.

A centralidade de proximidade permite a localização dos atores cujo esforço para se relacionar com o maior número possível de nós é o menor possível em função da menor distância dos demais atores da rede. Até que ponto uma boa classificação nessa variável repercute nas chances eleitorais?

$\mathrm{O}$ índice de proximidade média do quartil superior é 0,22 e a do inferior é 0,16 (Tabela 3). Detectamos 971 candidatos eleitos no quartil superior dessa centralidade, ou $59,8 \%$ do componente gigante. No quartil inferior encontramos 122 , ou $7,5 \%$.

Embora para a rede investigada a variável em questão não tenha o mesmo poder explicativo que a centralidade de grau, há uma associação significativa entre proximidade e desempenho eleitoral, e a chance de um candidato que compõe o quartil superior de centralidade de proximidade estar entre os eleitos é quase oito vezes maior que daquele que compõe o quartil inferior. Ademais, pudemos constatar a relação afirmada pela literatura de redes (Degenne e Forsé, 2007) entre proximidade e poder econômico: enquanto no quartil superior a receita média por candidato é de $R \$ 688.507,86$, no inferior ela é muito menor - R\$15.466,92.

Para Degenne e Forsé (2007), a centralidade de intermediação é uma proxy da influência, pois um ator com elevada capacidade de intermediação exerce papel de atravessador (broker), facilitando ou dificultando o fluxo de troca dos recursos transacionados, ao colocar-se nos caminhos mais curtos entre todos os nós que formam uma rede. Além disso, tal ator exerce papel de elo entre grupos. Qual a relevância dessa variável em uma rede de financiamento de campanha para a compreensão do desempenho de uma candidatura?

No quartil superior de centralidade de intermediação, encontramos um índice médio de 0,022 e 1.279 eleitos (78,7\% do componente gigante); no inferior, nenhum nó apresentou valores para a variável em tela e há apenas nove eleitos, ou 0,5\% (Tabela 3). A diferença entre as chances de um eleito compor o quartil superior em relação ao quartil inferior é de mais de 142 vezes. Portanto, centralidade de intermediação é uma variável com amplo poder explicativo na rede de financiamento eleitoral de 2010, permitindo afirmar a relevância da associação entre poder econômico, influência e sucesso eleitoral.

Analisadas em conjunto, as estatísticas de centralidade aplicadas às candidaturas explicitam uma topologia profundamente assimétrica, com diferenças expressivas de posicionalidade - há atores muito centrais e há atores muito periféricos mesmo no componente gigante, em que todos os nós estão conectados.

A referida assimetria está fortemente associada à viabilidade eleitoral das candidaturas, dado que, em todas as variáveis consideradas, candidatos com maior centralidade apresentam chances muito maiores de se eleger, especialmente aqueles 
com grande número de vínculos (grau) e posições privilegiadas no fluxo de recursos (intermediação).

$\mathrm{Na}$ medida em que foge ao escopo do artigo, uma análise aprofundada dos atributos desses candidatos centrais fica para o desenvolvimento futuro das investigações ${ }^{10}$. No entanto, uma exploração preliminar traz algumas indicações instigantes. A Tabela 4 possibilita a visualização do perfil desses candidatos em relação a dois desses atributos - gênero e ocupação:

Tabela 4

Gênero e ocupação dos candidatos conforme quartis de centralidade

\begin{tabular}{|c|c|c|c|c|c|c|c|c|c|c|c|c|}
\hline \multirow{2}{*}{ Gênero } & \multicolumn{4}{|c|}{ Centralidade de grau } & \multicolumn{4}{|c|}{ Centralidade de proximidade } & \multicolumn{4}{|c|}{$\begin{array}{c}\text { Centralidade de } \\
\text { intermediação }\end{array}$} \\
\hline & \multicolumn{2}{|c|}{$\begin{array}{c}\text { Quartil } \\
\text { superior }\end{array}$} & \multicolumn{2}{|c|}{$\begin{array}{l}\text { Quartil } \\
\text { inferior }\end{array}$} & \multicolumn{2}{|c|}{$\begin{array}{c}\text { Quartil } \\
\text { superior }\end{array}$} & \multicolumn{2}{|c|}{$\begin{array}{c}\text { Quartil } \\
\text { inferior }\end{array}$} & \multicolumn{2}{|c|}{$\begin{array}{l}\text { Quartil } \\
\text { superior }\end{array}$} & \multicolumn{2}{|c|}{$\begin{array}{l}\text { Quartil } \\
\text { inferior }\end{array}$} \\
\hline Masculino & 2936 & 82,1 & 2739 & 76,6 & 3009 & 84,2 & 2872 & 80,3 & 3090 & 86,4 & 2697 & 75,4 \\
\hline Feminino & 639 & 17,9 & 836 & 23,4 & 566 & 15,8 & 703 & 19,7 & 485 & 13,6 & 878 & 24,6 \\
\hline Agricultor & 31 & 0,9 & 32 & 0,9 & 25 & 0,7 & 32 & 0,9 & 31 & 0,9 & 40 & 1,1 \\
\hline $\begin{array}{l}\text { Dona de } \\
\text { casa }\end{array}$ & 5 & 0,1 & 47 & 1,3 & 12 & 0,3 & $\underline{28}$ & 0,8 & 5 & 0,1 & 104 & 2,9 \\
\hline Economista & 41 & 1,1 & 9 & 0,3 & 42 & 1,2 & 18 & 0,5 & 44 & 1,3 & 16 & 0,4 \\
\hline Empresário & 313 & 8,8 & 277 & 7,7 & 283 & 7,9 & 280 & 7,8 & 320 & 9,2 & 550 & 15,4 \\
\hline
\end{tabular}

Fonte: Elaboração própria com base nos dados do TSE (Brasil, 2014).

\footnotetext{
10 Para um aprofundamento da questão, diversos trabalhos podem ser consultados. Costa e Codato (2013), por exemplo, analisam o perfil profissiográfico da classe política brasileira a partir dos senadores; Junckes et al. (2015) exploram as redes de financiamento eleitoral sob um enfoque de gênero.
} 
Nota-se que, em todos os casos, a proporção de mulheres é sempre maior nos quartis inferiores de centralidade. No tocante à ocupação, há uma baixíssima participação de donas de casa, embora o número seja expressivamente maior nos quartis inferiores. O dado mais interessante é que em todos os quartis superiores os políticos são os profissionais mais frequentes.

Além de indicar uma profissionalização da política, especialmente via reeleição, os achados a partir das características individuais dos candidatos sinalizam para uma questão de método: pesquisas sobre eleições exclusivamente baseadas em atributos precisariam passar a considerar a assimetria de posições nas redes relacionais e não apenas os atributos per se, descolados dos vínculos entre os atores. Trata-se de um indicativo promissor para a agenda de estudos sobre o financiamento político.

A relação entre posição na topologia da rede e desempenho eleitoral foi amplamente demonstrada no que concerne às candidaturas. As medidas de centralidade utilizadas confirmam, em síntese, que para ser bem-sucedido eleitoralmente um candidato deve ter vários financiadores, estar próximo dos demais atores e colocar-se em posições privilegiadas nos fluxos relacionais que estes estabelecem entre si. E o que as mesmas medidas dizem acerca dos demais atores da rede de financiamento das eleições de 2010 ?

A hipótese é de que financiadores centrais investem com mais assertividade que os doadores em seu conjunto, ou seja, fazem apostas direcionadas nos partidos e nos candidatos mais exitosos. Para tanto, dividimos os financiadores em dois tipos: doadores privados, sejam pessoas físicas, sejam pessoas jurídicas, e agentes partidários, incluindo diretórios e comitês financeiros agregados por sigla em cada unidade da federação.

No intuito de identificar os financiadores privados centrais, montamos listas com os 100 desses atores mais bem posicionados nos rankings das centralidades de grau, proximidade, intermediação e autovetor bem como a dos 100 maiores em valores doados $^{11}$. Mesclamos as listas, obtendo uma relação com 189 financiadores que se repetem nas cinco listas originais - sendo 178 pessoas jurídicas e apenas 11 pessoas físicas.

Duas pessoas físicas e 22 empresas optaram por doar exclusivamente para agentes partidários. Os maiores beneficiários dessas doações foram os partidos PT, PSDB e PMDB, que, como se depreende dos resultados das urnas, foram os grandes vencedores do pleito em exame.

\footnotetext{
${ }^{11}$ Optamos por esse procedimento em função da maior consistência gerada quando os atores resultantes estiveram presentes nas listas ordenadas de centralidades. Isso se mostrou necessário, no caso dos financiadores, porque, diferentemente dos candidatos, eles não apresentam uma variável que possibilite a verificação direta de seu desempenho (por exemplo, votação e situação de urna). A variável autovetor é especialmente pertinente à análise dos financiadores e foi incluída nessa parte do artigo em face do postulado de que, quando esses atores são players relevantes, eles tendem a se aproximar de candidatos que ampliem sua influência potencial na rede. A explicação dessa medida pode ser obtida em Newman (2010, p. 168-192 passim).
} 
Os demais 165 financiadores - 156 empresas e nove pessoas físicas - fizeram 4.315 doações diretas, que somaram $\mathrm{R} \$ 412.587 .193,00$ para 1.787 candidatos. Destes, 763 foram eleitos, ou $46,2 \%$ dos eleitos no componente gigante, percentual sensivelmente superior aos $11,3 \%$ de eleitos entre os candidatos no mesmo componente. Os dados ficam mais eloquentes ao refinarmos a análise por cargo. Como mostra a Tabela 5, afora o óbvio direcionamento para a disputa presidencial, quanto mais expressivo o cargo em termos de poder de decisão sobre políticas e recursos públicos, maior a porcentagem de candidatos eleitos apoiados por financiadores privados centrais, que estão claramente mais interessados em eleger governadores e senadores do que deputados estaduais, por exemplo.

Ressalte-se que esses 165 financiadores, malgrado apoiarem uma grande quantidade de candidatos e partidos, representavam apenas $0,8 \%$ dos doadores privados na campanha de 2010. Portanto, menos de $1 \%$ dos doadores privados, em sua ampla maioria os principais grupos empresariais do país, financiaram diretamente, dentre os eleitos, $85 \%$ dos governadores, $83 \%$ dos senadores, $64 \%$ dos deputados federais e $34 \%$ dos deputados estaduais.

Tabela 5

Candidatos eleitos financiados diretamente por um ou mais financiadores centrais

\begin{tabular}{|l|c|c|c|}
\hline \multicolumn{1}{|c|}{ Cargo } & $\begin{array}{c}\text { Vagas em } \\
\text { disputa }\end{array}$ & $\begin{array}{c}\text { N cand. } \\
\text { financiados }\end{array}$ & \% \\
\hline Presidente & 1 & 1 & 100,0 \\
\hline Governador & 27 & 23 & 85,2 \\
\hline Senador & 54 & 45 & 83,3 \\
\hline Deputado federal & 513 & 332 & 64,7 \\
\hline Deputado estadual & 1056 & 362 & 34,3 \\
\hline Total & 1651 & 763 & 46,2 \\
\hline
\end{tabular}

Fonte: Elaboração própria com base em dados do TSE (Brasil, 2014).

É plausível sustentar que os investimentos eleitorais visam a manter e ampliar o status, os papéis e a influência social, política e econômica decorrentes. Para esse fim, além dos 412 milhões de reais destinados diretamente aos candidatos, os financiadores privados centrais fizeram chegar aos seus apoiados outros 866 milhões de reais através dos agentes partidários que ocupam posições privilegiadas na topologia da rede.

Para identificarmos os agentes partidários centrais, realizamos os mesmos procedimentos de cálculo e análise empregados para os financiadores privados ${ }^{12}$. Como resultado, 165 atores desse tipo se repetem nas cinco listas.

De um lado, constatamos clara interface entre financiadores e agentes partidários centrais. Dentre aqueles atores, 165 empresas e 11 pessoas físicas doaram

\footnotetext{
12 Mesclamos as listas dos 100 atores mais bem posicionados nos rankings das centralidades de grau, proximidade, intermediação e autovetor, além dos 100 maiores em valores doados.
} 
diretamente para 145 dos agentes partidários em questão. Os valores transacionados superam o dobro dos recebidos pelos candidatos, somando R\$ 866.571.859,00, uma média de $\mathrm{R} \$ 5.976 .357,65$ para cada agente partidário.

De outro lado, o papel estratégico principal que estes desempenham é o de intermediador de recursos, vale dizer, atravessadores (brokers), assumindo importância singular na rede de financiamento, inferência validada pelos dados a seguir.

Os 165 agentes partidários com alta centralidade financiaram diretamente 8.165 candidatos, o que equivale a $57,1 \%$ das 14.299 candidaturas do componente gigante sendo 1.202 exitosas, ou 74\% dos eleitos nesse componente. Os candidatos receberam R\$ 1.155.322.850,00 em 9.738 doações provenientes desses agentes. Esse valor representa $75 \%$ da receita dos agentes partidários centrais, porcentual que se origina de apenas $0,08 \%$ dos doadores privados de campanha em 2010, evidenciando a procedência concentrada de recursos em algumas poucas dezenas de doadores.

A representação dos fluxos de recursos entre doadores centrais, agentes partidários e candidatos eleitos e não eleitos pode ser observada na Figura 6 . Nesse grafo o tamanho dos nós é proporcional ao montante doado ou recebido e a espessura das arestas (linhas) corresponde ao volume de recursos transacionado:

Figura 6

Grafo da rede de financiamento/financiadores centrais, nós agregados por tipo de ator

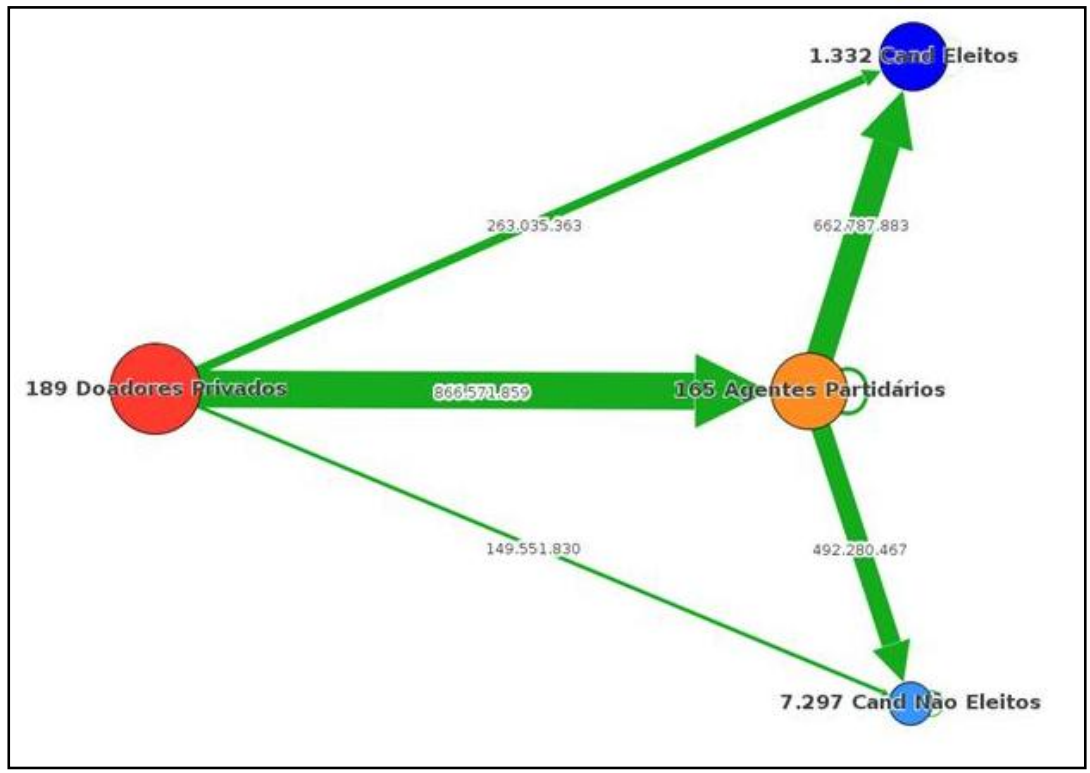

Fonte: Elaboração própria com base em dados do TSE (Brasil, 2014).

A Figura 6 mostra que, para os eleitos (15\% dos candidatos), foram direcionados $67 \%$ dos recursos, enquanto para os demais $85 \%$ dos candidatos, os não eleitos, foram 
destinados apenas $33 \%$ dos recursos dos doadores centrais. É flagrante, também, a diferença entre o direcionamento que fazem esses doadores e aquele relacionado aos doadores privados no geral (Figura 2, primeiro grafo agregado).

O volume das doações privadas para candidatos e agentes partidários na rede global é equânime ( $R \$ 1,1$ bilhão para cada tipo), enquanto na rede específica da Figura 4 doadores privados centrais destinam duas vezes mais recursos para os agentes partidários do que para os candidatos.

Diante da eloquência dos números, vale a pena deter-se na sub-rede forjada a partir das doações que os financiadores privados e os agentes partidários centrais efetuaram diretamente aos candidatos e a tradução dessa rede em sucesso nos investimentos efetuados. Trata-se de uma rede bastante densa, com 8.959 nós e 14.053 arestas e o expressivo valor de $\mathrm{R} \$ 1.567 .910 .043,00^{13}$. Os financiadores centrais (privados e agentes partidários) doaram para 8.629 candidatos, dos quais 1.332 foram eleitos.

Frise-se que apenas $0,2 \%$ dos 225 mil doadores que participaram do processo eleitoral financiaram diretamente $81 \%$ dos 1.651 eleitos em 2010. Não poderia causar nenhuma surpresa que tal poderio financeiro, associado à direcionalidade assertiva dos recursos, apresente como resultado uma rede de financiamento político-financeira que alcança, além da presidente, $100 \%$ dos governadores, $98 \%$ dos senadores, $91 \%$ dos deputados federais e $74 \%$ dos deputados estaduais eleitos (Tabela 6):

Tabela 6

Candidatos eleitos financiados diretamente por um ou mais doadores centrais (pessoas físicas e agentes partidários)

\begin{tabular}{|l|c|c|c|}
\hline \multicolumn{1}{|c|}{ Cargo } & $\begin{array}{c}\text { Vagas em } \\
\text { disputa }\end{array}$ & No de cand. financiados & \% \\
\hline Presidente & 1 & 1 & 100,0 \\
\hline Governador & 27 & 27 & 100,0 \\
\hline Senador & 54 & 53 & 98,1 \\
\hline Deputado federal & 513 & 469 & 91,4 \\
\hline Deputado estadual & 1056 & 782 & 74,1 \\
\hline Total & 1651 & 1332 & 80,7 \\
\hline
\end{tabular}

Fonte: Elaboração própria com base em dados do TSE (Brasil, 2014)

A Tabela 6 mostra que, quando se agregam os financiadores privados e agentes partidários centrais, reforça-se a inferência de que os doadores centrais são especialmente assertivos quando se trata dos principais agentes políticos. Quanto maior o potencial de decisão maior a concentração proporcional de doadores centrais entre

\footnotetext{
${ }^{13}$ É necessário considerar que se trata de valor circulado, isto é, contabiliza-se a origem e também os repasses desses recursos dentro da rede.
} 
seus financiadores, especialmente nos casos de presidente, governador e senador. Excluindo-se os candidatos às Assembleias Legislativas, entre os quais redes de apoio exclusivamente locais são mais recorrentes, os doadores centrais financiaram $92,4 \%$ dos eleitos.

Esses achados contribuem para reforçar a posição presente em pesquisas citadas por Mancuso (2015, p. 163-166), que exploram a associação entre as doações e as expectativas de distintas formas de retribuição, tais como acesso ao financiamento de bancos públicos, obtenção de contratos com o governo, incremento no desempenho mercantil ou benefícios tributários e outros.

Para melhor visualizar o núcleo estrutural configurado pelo financiamento de campanha, além dos rankings e filtros já aplicados anteriormente, executamos a redução do componente gigante a partir da centralidade de grau. O procedimento adotado consistiu em manter apenas nós com 10 ou mais conexões, um filtro, diga-se, não muito exigente se considerarmos que não há limite à quantidade de doações. Como resultado, o componente gigante se reduz para 5.038 nós, ou 2,1\% do original (Figura 7):

\section{Figura 7}

\section{Grafo da rede de financiamento eleitoral de 2010, componente gigante reduzido em grau 10}

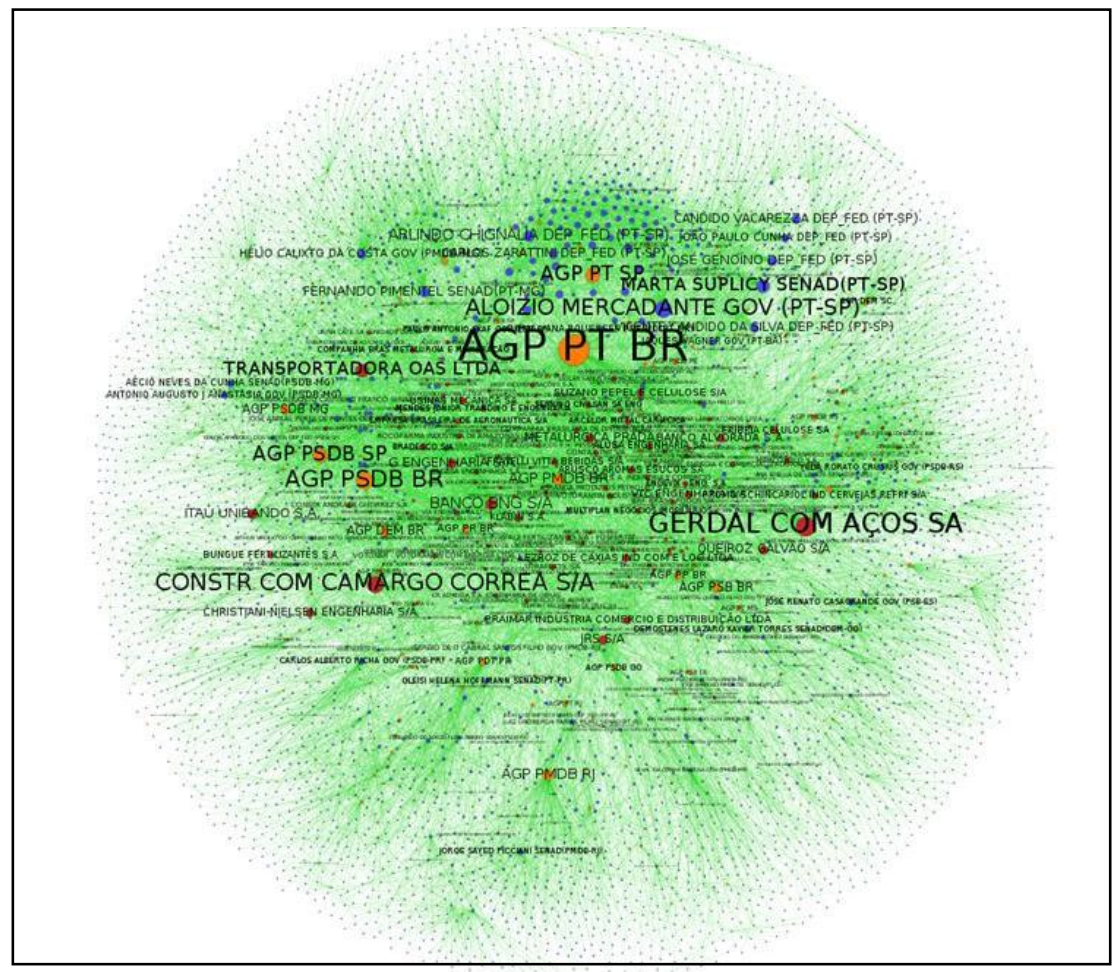

Fonte: Elaboração própria com base em dados do TSE (Brasil, 2014). Nós graduados por centralidade de autovetor, distribuição OpenOrd. Nós azuis: candidatos; vermelhos: doadores privados; laranjas: agentes partidários. 
Foram bastante preservados os agentes partidários. Com a redução, permanecem 339, ou 67,5\% dos 502 que havia no componente gigante original. E quais foram os atores eliminados? As pessoas físicas, principalmente. No componente reduzido de grau 10 restaram apenas 19 delas, ou 0,009\% das 204.078 que constituem o componente gigante original. Ou seja, aqueles atores que representavam a quase totalidade dos financiadores privados praticamente desaparecem.

Pessoas jurídicas sofreram redução importante, restando 345 no componente gigante reduzido, ou seja, $1,6 \%$ das 21.096 presentes no componente gigante original. Considerando os perfis das PJs que se mantiveram detectamos que em geral são grandes corporações, enquanto as eliminadas pela redução são empresas de menor porte e atuação regional.

A importância desse corte topológico reside no fato de que identificamos uma elite na rede de financiamento eleitoral. A aplicação de um filtro que elimina praticamente $98 \%$ dos participantes do processo demonstra que no Brasil 0,1\% dos doadores financia direta ou indiretamente mais de $80 \%$ dos candidatos eleitos.

\section{Considerações finais}

A análise da rede de financiamento eleitoral de 2010 demonstra que as maiores chances eleitorais dos candidatos, assim como a assertividade dos doadores em identificar e financiar o conjunto de candidaturas mais exitosas, estão positivamente relacionadas à ocupação de posições centrais na teia de relacionamentos constituída pelo financiamento de campanha.

Trata-se de uma rede altamente conectada, pois mais de $90 \%$ dos atores participantes estão direta ou indiretamente ligados entre si em apenas uma sub-rede (componente gigante). Estar fora desse componente praticamente elimina um ator das possibilidades de êxito, seja ele candidato ou financiador. Por essa razão, identificamos os agentes centrais da rede no componente gigante.

O resultado é uma topologia bastante assimétrica, na qual a posicionalidade dos atores apresenta diferenças significativas, havendo atores muito centrais e também atores muito periféricos. Tal assimetria está fortemente associada ao desempenho eleitoral dos atores na rede.

Para os candidatos, ocupar posições centrais amplia enormemente as chances de eleição. Em suma, isso implica ter vários financiadores, estar próximo dos demais atores e colocar-se em posições privilegiadas nos fluxos relacionais que essas pessoas estabelecem entre si.

A dinâmica se repete no caso dos doadores - sejam eles financiadores privados ou agentes partidários que intermedeiam as doações daqueles. A maior ou menor assertividade do financiador, i.e., financiar aquele que será eleito, está relacionada ao maior número de doações (grau), à menor distância do conjunto dos demais atores da rede (proximidade), à capacidade de se colocar em posições privilegiadas nos fluxos 
relacionais (intermediação) e, também, de se posicionar muito perto dos atores centrais (autovetor).

A configuração de uma elite do poder formada por grandes financiadores, agentes partidários centrais e candidatos, normalmente políticos profissionais, é evidenciada pela rede reduzida, da qual foram eliminados $98 \%$ dos nós do componente gigante original. De forma surpreendente, nos $2 \%$ restantes dos nós da rede ficam preservados $90 \%$ dos candidatos eleitos. Esta é, com efeito, a principal característica estrutural da rede de financiamento eleitoral, ao menos em 2010.

Seria ingênuo sugerir ou indicar que tal topologia é aleatória. Ser central não é uma questão de simples escolha, mas sim de dispor de recursos, capitais materiais e simbólicos prévios aos pleitos. Na rede pesquisada trata-se de uma elite econômica formada pelos principais grupos empresariais do país financiando uma elite política composta de agentes partidários institucionais e candidatos cuja profissão declarada com mais frequência é justamente a de político.

Os dados da rede sinalizam ainda uma estratégia na qual os partidos assomam como atravessadores (brokers) de recursos, especialmente quando as doações provêm dos doadores privados centrais. Financiadores privados e agentes partidários centrais apresentam ampla interface entre si e assertividade na identificação e direcionamento de recursos para as candidaturas vencedoras, reconhecendo-se, por óbvio, que estas frequentemente integram as cúpulas dos partidos.

A metodologia de análise de redes permitiu identificar um núcleo composto por apenas $0,2 \%$ dos doadores originais (financiadores privados e agentes partidários). Demonstramos que esse reduzido grupo financiou diretamente $81 \%$ dos 1.651 eleitos em 2010, constituindo uma rede de financiamento político-financeira que atinge, além da presidente, $100 \%$ dos governadores, $98 \%$ dos senadores, $91 \%$ dos deputados federais e $74 \%$ dos deputados estaduais eleitos.

Esse conjunto de achados possibilita apreender sentidos histórico-políticos e teórico-metodológicos das redes de financiamento. Destaca-se, nesse sentido, a identificação de papéis exercidos por financiadores, agentes partidários e candidatos a partir do mapeamento do fluxo de transferência de recursos entre tais atores, especialmente quando eles são agregados. Tornou-se clara, então, a atuação dos comitês financeiros e diretórios, recebendo recursos dos financiadores privados e repassando-os aos candidatos que melhor se ajustam às estratégias definidas pelas elites partidárias.

Tal estratégia tem sido bastante discutida na literatura, mas pouco demonstrada. Pelo formato diferenciado de exploração e pela análise dos dados de prestação de contas das campanhas, o presente artigo permite a superação parcial dessa limitação imposta pela figura da "doação oculta" ou "ocultada" ao mesmo tempo em que revela, pela dinâmica das transferências de recursos, as alianças e movimentação estratégica.

Embora o movimento de ocultação não tenha sido explorado neste artigo, a identificação dos atores e o desvelamento da dinâmica torna isso possível em futuros 
RODRIGO ROSSI HOROCHOVSKI ET AL.

trabalhos através de agregações e projeções baseadas em variáveis como partido e unidades da federação.

Destaca-se também, entre os resultados, a identificação dos papéis desempenhados pelos atores em função de suas posições relativas na estrutura de poder estabelecida na rede de financiamento eleitoral.

Os agentes mais periféricos e desconectados - sejam eles financiadores, agentes partidários ou candidatos - participam do jogo com chances de vitória próximas de zero, ao menos no que concerne ao desempenho eleitoral de agremiações e candidaturas. Os agentes mais centrais, por seu turno, formam uma sub-rede muito densa que conforma a elite política do país. Esse núcleo detém os recursos para viabilizar o conjunto de estratégias postas em ação por partidos e candidatos vitoriosos.

Nesse quadro, merece atenção a atuação dos comitês e diretórios. Mais do que eclipsar os vínculos entre financiadores e candidatos, os agentes partidários colocam-se como operadores centrais na intermediação dos recursos transacionados, permitindo ou bloqueando fluxos entre os doadores iniciais, especialmente as pessoas jurídicas, e os destinatários finais dos recursos financeiros envolvidos.

Os agentes partidários apresentam-se também como integradores dos diversos atores que compõem a rede, notadamente candidatos a diferentes cargos localizados em todo o território nacional. Isso sugere a possibilidade de aprofundar as pesquisas sobre o papel dos partidos tanto do ponto de vista de construtor de um projeto de sociedade quanto de instância central no provimento de estrutura nas batalhas eleitorais, centralizando processos decisórios e estabelecendo um controle dos seus filiados por meio dessas estratégias.

Estratégias integradoras são nítidas também entre os financiadores centrais, ao doarem para partidos e candidatos os mais diversos, localizados nos mais diferentes pontos do espaço territorial brasileiro e nos mais diferentes partidos. Tal atuação ocorre, todavia, com nítida centralidade na topologia da rede e é dirigida àqueles com potencial mais alto de influência e veto sobre políticas públicas mais abrangentes que possam beneficiar os financiadores.

Em face dessas estratégias, cabe aos candidatos, de maneira mais formalizada ou intuitiva, compreender e jogar o jogo, colocando-se em posição de exercer centralidade e, consequentemente, ser bem-sucedidos eleitoralmente na medida em que, como demonstrado, ambos os elementos estão diretamente relacionados. Todavia, não se trata de algo que se obtém pela "vontade" de um ator singular, haja vista os relacionamentos entre os candidatos e seus financiadores produzirem e reproduzirem uma dinâmica de centralização, sejam estes empresas ou partidos, concentrando recursos numa pequena parcela de candidaturas mais viáveis, com grande presença de políticos experientes, em geral homens.

As inferências acima sugerem a necessidade de investigar outros elementos no desenvolvimento da pesquisa. É necessário aprofundar o papel dos partidos identificando 
especificidades entre eles, assim como as muitas diferenças entre as campanhas em diversas unidades da federação.

Pode-se investir, ainda, nos fatores e atributos dos agentes relacionados a posições mais vantajosas na topologia das redes de financiamento - um dos terrenos que parecem férteis nesse sentido é o estudo das carreiras e ocupações dos agentes vis-à-vis suas posições no centro ou na periferia das redes de financiamento. Estamos desenvolvendo tais estudos.

Salientamos, ainda, a pertinência de explorar os papéis diferenciados exercidos por candidatos a diferentes cargos - é possível, por exemplo, testar a hipótese de candidaturas majoritárias e de membros do "alto clero" parlamentar também exercerem as estratégias de eclipsamento, intermediação, integração e centralização dos fluxos decisórios.

Rodrigo Rossi Horochovski - Curso de Gestão Pública. Setor Litoral. Universidade Federal do Paraná. E-mail: <rodrigoh33@gmail.com>.

Ivan Jairo Junckes - Curso de Gestão Pública. Setor Litoral. Universidade Federal do Paraná. E-mail: <ivanjairojunckes@gmail.com>.

Edson Armando Silva - Departamento de História. Setor de Ciências Humanas Letras e Artes. Universidade Estadual de Ponta Grossa. E-mail: <edameister@gmail.com>.

Joseli Maria Silva - Departamento de Geografia. Setor de Ciências Exatas. Universidade Estadual de Ponta Grossa. E-mail: <joseli.genero@gmail.com>.

Neilor Fermino Camargo - Curso de Informática e Cidadania. Setor Litoral. Universidade Federal do Paraná. Doutorando em Ciência Política, Universidade Federal do Paraná. E-mail: <camargon@gmail.com>.

\section{Referências bibliográficas}

BAtAgeL, V. Large-scale network analysis. In: Scott, J.; CARrington, P. J. (orgs.). The Sage Handbook of Social Network Analysis. London: Thousand Oaks, Calif: Sage, 2011.

BourdoukAN, A. Y. "O bolso e a urna: financiamento político em perspectiva comparada". Tese de Doutorado em Ciência Política. Universidade de São Paulo (USP), São Paulo, 2009.

BRASIL. Tribunal Superior Eleitoral (TSE). Prestação de contas 2010 [online]. Disponível em: <http://www.tse.jus.br/eleicoes/estatisticas/repositorio-de-dados-eleitorais>. Acesso em: 14 set. 2014.

Cervi, E. U. "Financiamento de campanhas e desempenho eleitoral no Brasil: análise das contribuições de pessoas físicas, jurídicas e partidos políticos às eleições de 2008 nas capitais de Estado". Revista Brasileira de Ciência Política, Brasília, vol. 1, no 4, p. 135-167, 2010.

CostA, L. D.; CoDATo, A. Profissionalização ou popularização da classe política brasileira? Um perfil dos senadores da República. In: MARENCO DOS SANTOS, A. (org.). Os eleitos: representações e carreiras políticas em democracias. Porto Alegre: Editora UFRGS, 2013.

DEGENNE, A.; ForsÉ, M. Introducing social networks. Sage: Londres, 2007. 
RODRIGO ROSSI HOROCHOVSKI ET AL.

Figueiredo Filho, D. B. "O elo corporativo? Grupos de interesse, financiamento de campanha e regulação eleitoral". Dissertação de Mestrado em Ciência Política. Universidade Federal de Pernambuco (UFPE), Recife, 2009.

FREEMAN, L. C. "Centrality in social networks: conceptual clarification". Social Networks, vol. 1, no 3, p. 215-239, 1979.

HOROCHOVSKI, R. R., et al. "Redes de partidos políticos tecidas por financiadores: um estudo das eleições de 2010 no Brasil". Teoria \& Sociedade, Belo Horizonte, vol. 23, no 2, p. 49-78, 2015.

JUNCKES, I. J., et al. "As mulheres na rede de financiamento eleitoral e seu desempenho nas eleições de 2010 no Brasil: a dinâmica de exclusão, isolamento e marginalização no poder político". Revista Latino-Americana de Geografia e Gênero, Ponta Grossa, vol. 6, p. 25-47, jan.-jul. 2015.

Lemos, L. B.; MARCelino, D.; Pederiva, J. H. "Por que dinheiro importa: a dinâmica de contribuições eleitorais para o Congresso Nacional em 2002 e 2006". Opinião Pública, Campinas, vol. 16, no 2, p. 366-393, nov. 2010.

LimA, S. M. P. Prestação de contas e financiamento de campanhas eleitorais. Curitiba: Juruá, 2012.

Lodoño; J. F.; Zovatto, D. Latin America. In: Falguera, E.; Jones, S.; Ohman, M. (eds.). Funding of political parties and election campaigns: a handbook on political finance. Stockholm: Idea, 2014.

MAncuso, W. P. "Investimento eleitoral no Brasil: balanço da literatura (2001-2012) e agenda de pesquisa". Revista de Sociologia e Política, Curitiba, vol. 23, no 54, p. 155-183, jun. 2015.

NeWman, M. E. J. Networks: an introduction. Oxford, NY: Oxford University Press, 2010.

OHMAn, M. Introduction to political finance. In: FAlguera, E.; JOnes, S.; OhmAN, M. (eds.). Funding of political parties and election campaigns: a handbook on political finance. Stockholm: Idea, 2014.

Peixoto, V. M. "Financiamento de campanhas: o Brasil em perspectiva comparada". Perspectivas, São Paulo, vol. 35, p. 91-116, jan.-jun. 2009.

"Financiamento de campanhas nas eleições legislativas brasileiras em 2010". Em Debate, Belo Horizonte, vol. 6, p. 36-54, 2014.

SACCHET, T.; SPECK, B. W. "Financiamento eleitoral, representação política e gênero: uma análise das eleições de 2006". Opinião Pública, Campinas, vol. 18, no 1, p. 177-197, jun., 2012.

Samuels, D. "Money, elections, and democracy in Brazil". Latin American Politics and Society, Miami (FL), vol. 43, n० 2, p. 27-48, Summer, 2001.

SANTOS, M. L., et al. "Financiamento de campanha e apoio parlamentar à Agenda Legislativa da Indústria na Câmara dos Deputados". Opinião Pública, Campinas, vol. 21, nº 1, abr. 2015, p. 33-59.

SAWICKI, F. Por uma sociologia dos meios e das redes partidárias. In: MARENCo dos SANTOS, A. (org.). Os eleitos: representações e carreiras políticas em democracias. Porto Alegre: Editora UFRGS, 2013.

SCHLiCKMANN, D. G. Financiamento de campanhas eleitorais. Curitiba: Juruá, 2014.

SPECK, B. W. "Reagir a escândalos ou perseguir ideais? A regulação do financiamento político no Brasil". Cadernos Adenauer, São Paulo, vol. 6, n 2, p. 123-159, 2005.

SpeCK, B. W.; MANCuso, W. P. "Financiamento de campanhas e prestação de contas". Cadernos Adenauer, São Paulo, vol. 15, p. 135-150, 2014.

ZovatTo, D. "Financiamento dos partidos e campanhas eleitorais na América Latina: uma análise comparada". Opinião Pública, Campinas, vol. 11, no 2, p. 287-336, out. 2005. 


\section{Resumo}

Estruturas de poder nas redes de financiamento político nas eleições de 2010 no Brasil

Este artigo analisa os 299.968 relacionamentos estabelecidos entre os 251.665 doadores e/ou receptores de recursos financeiros legais abrangidos pelas prestações de contas das campanhas nas eleições de 2010 no Brasil, englobando todos os candidatos e partidos. Aplica-se aos dados do Tribunal Superior Eleitoral (TSE) a metodologia de análise de redes sociais e tratamentos estatísticos complementares para a exploração da topologia das sub-redes (componentes) e dos cálculos de centralidade dos atores - candidatos, agentes partidários e financiadores privados. Os resultados expõem a alta conectividade e assimetria da rede de financiamento eleitoral no Brasil e mostram que o posicionamento dos atores em estratos da rede é determinante para o desempenho tanto de candidatos quanto de financiadores, revelando, de uma forma inédita, uma elite no poder políticoeleitoral brasileiro.

Palavras-chave: financiamento político; análise de redes sociais; desempenho eleitoral; Brasil; eleições 2010

\section{Abstract}

Power structures in the political finance networks in elections of 2010 in Brazil

This article analyses 299,968 relationships established between 251,665 actors (donors and/or recipients) of financial legal resources declared by candidates and parties in all positions at stake in the 2010 elections in Brazil. Data from the Tribunal Superior Eleitoral (Superior Electoral Court) was used, together with the methodology of social network analysis and complementary statistical procedures, to explore the topology of the subnets (components) and of the calculations of the centrality of the actors - candidates, party agents and private funders. The results show the high connectivity and asymmetry of the campaign finance network in Brazil and they expose that the positioning of the actors in the network layers is crucial to the performances of both the candidates and the funders, revealing, in an unprecedented way, the existence of a political elite within the Brazilian electoral system.

Keywords: political finance; social network analysis; electoral performance; Brazil, 2010 elections

\section{Resumen}

Estructuras de poder en redes de financiamiento político en las elecciones de 2010 en Brasil

Este artículo analiza las 299.968 relaciones que se establecen entre los 251.665 donadores y/o los beneficiarios de recursos legales cubiertos por las presentaciones de cuentas de las campañas en las elecciones de 2010 en Brasil, lo que abarca todos los candidatos y partidos. Se aplican a los datos del Tribunal Superior Electoral (TSE) la metodología de análisis de redes sociales y métodos estadísticos complementarios para la explotación de la topología de subredes (componentes) y cálculos de centralidad de los actores - candidatos, representantes de los partidos y los aportantes privados. Los resultados exponen la alta conectividad y la asimetría que hay en la red de financiamiento de campañas en Brasil y muestran que el posicionamiento de los actores en las capas de la red es crucial para el desempeño de ambos, candidatos y donadores, lo que revela de una manera sin precedentes una élite en el poder político electoral brasileño.

Palabras clave: financiamiento político; análisis de redes sociales; rendimiento electoral; Brasil; elecciones 2010 


\section{Résumé}

Les structures de pouvoir dans les réseaux de financement politique lors des élections de 2010 au Brésil

Cet article se penche sur les 299.968 rapports établis entre les 251.665 donateurs et/ou bénéficiaires de financement légal contemplé par la présentation des comptes de campagne des élections de 2010 au Brésil, et qui englobe tous les candidats et tous les partis. On applique la méthodologie d'analyse des réseaux sociaux et des méthodes statistiques complémentaires aux données du Tribunal Électoral Supérieur (TSE) pour exploiter la topologie des sous-réseaux (composants) et des calculs de centralité des acteurs - candidats, représentants des partis et personnes faisant des dons privés. Les résultats exposent la grande connectivité et l'asymétrie du réseau de financement de campagne au Brésil et ils montrent que le positionnement des acteurs dans certaines strates du réseau est crucial, aussi bien pour la performance des candidats que celle des donateurs, ce qui révèle, d'une manière inédite, la présence d'une élite au sein du pouvoir politico-électoral brésilien.

Mots-clés: financement politique; analyse de réseaux sociaux; performance électorale; Brésil; élections 2010

Artigo submetido em março de 2015. Versão final aprovada em dezembro de 2015. 